\title{
Two New Shallow-water Mysids of the Genus Heteromysis (Crustacea: Mysidacea) from a Submarine Cave of Christmas Island, Eastern Indian Ocean
}

\author{
Yukio Hanamura ${ }^{1}$ and Tomoki Kase ${ }^{2}$ \\ ${ }^{1}$ National Research Institute of Fisheries and Environment of Inland Sea, \\ Ohno-cho, Saeki-gun, Hiroshima, 739-0452 Japan \\ E-mail: hanamura@nnf.affrc.go.jp \\ ${ }^{2}$ Department of Geology, National Science Museum, Tokyo, \\ 2-23-1 Hyakunin-cho, Shinjuku-ku, Tokyo, 169-0073 Japan \\ E-mail: kase@kahaku.go.jp
}

(Received 30 August 2000; Accepted 22 December 2000)

\begin{abstract}
Two new species of the shallow-water mysid genus Heteromysis (Crustacea: Mysidacea) are reported from a submarine cave on Christmas Island, eastern Indian Ocean. Heteromysis dentata sp. nov. is characterized by eyes without ocular processes, the telson with lateral spines along its distal half, the posteromedian cleft of the telson with spinules along its entire margin, and the four posterior thoracic endopods each with a seven-segmented carpopropodus. Heteromysis longiloba sp. nov. is characterized by eyes without ocular processes, the telson with lateral spines along slightly more than its posterior half, the posteromedian telson cleft with spinules only along its anterior margin, and the inward-curving endopods of the uropods bearing 12 mesial spines. The Indo-Pacific species of Heteromysis are briefly reviewed.

Key Words: Crustacea, Mysidacea, Heteromysis, new species, submarine cave, Indian Ocean.
\end{abstract}

The genus Heteromysis is placed in the tribe Heteromysini of the family Mysidae and currently includes over 60 species from the tropical and subtropical regions of the world. Taxonomic studies of the Indo-Pacific Heteromysis species have been made by several authors, notably W. M. Tattersall (1922, 1927a, b), O. S. Tattersall (1967), Băcescu (1979, 1983, 1986), Băcescu and Bruce (1980), and Murano (1988, 1998).

A recent survey, conducted as a part of extensive faunal research of submarine caves in the Indo-Pacific, yielded small collections of mysids from Christmas Island in the eastern Indian Ocean. The sample included two previously unknown species of Heteromysis, and they are described and illustrated here. In addition, the Indo-Pacific species of Heteromysis are briefly reviewed and their key characteristics are presented.

The type specimens are deposited in the Western Australian Museum, Perth (WAM), and the National Science Museum, Tokyo (NSMT). 


\section{Systematic accounts \\ Genus Heteromysis S. I. Smith, 1873 \\ Heteromysis dentata sp. nov.}

(Figs 1, 2)

Material. Holotype: ovigerous female, $4.4 \mathrm{~mm}$ in total length (WAM C 24973), stn. XM2, "Thundercliff Cave" diving site, north side of Christmas Island, $10^{\circ} 28^{\prime} 21.3^{\prime \prime} \mathrm{S}, 105^{\circ} 36^{\prime} 24.6^{\prime \prime} \mathrm{E}, 30$ Nov. 1999 , limestone cave more than $100 \mathrm{~m}$ long, seemingly connected to land limestone caves, $1.3-6 \mathrm{~m}$ deep, totally dark inside, with calcareous and muddy sand bottom, salinity $32 \%$, leg. S. Ohashi, S. Kinjo, T. Kase, I. Hayami, Y. Kano, and L. Kirkendale. Paratype: female, $4.0 \mathrm{~mm}$ in total length (NSMT), data same as for holotype.

Description. Body moderately robust, slightly depressed dorsoventrally (Fig. 1a). Rostrum triangular, directed slightly downwards, reaching midlength of first segment of antennular peduncle, lateral margin slightly concave (Fig. 1b). Carapace rounded dorsally, cervical sulcus indistinct; posterior margin excavate, leaving last thoracic somite uncovered in dorsal view; anterolateral margin rounded (Fig. 1a, b). Ventral sternites without processes.

Abdomen with anterior 5 somites subequal in length, sixth somite 1.33 times as long as fifth (Fig. 1a). No median ventral process present on pleon. Telson as long as or slightly longer than sixth abdominal somite, 1.3 times as long as basal width, subtriangular; lateral margins weakly concave, armed laterally with 5 spines on posterior two-fifths of each side, these spines increasing in length distally; apical lobe with 2 terminal spines, outer spine about 2.5 times as long as inner one; posteromedian cleft occupying one-fifth of length of telson, armed with 16-17 spinules along almost its entire margin, posteriormost spinule reaching base of apical spine (Fig. 1c, d).

Eye with cornea well pigmented, slightly narrower than stalk, without ocular process; mesial margin of eyestalk slightly hispid (Fig. 1b). Antennular peduncle robust (Fig. 1f); first segment with anterolateral corner strongly produced and tipped with several setae; second segment shortest, articulating obliquely with third segment, and with setae at distomesial margin; third segment widest, with seta near midlength of mesial margin, and 2 ordinary setae and spine with acuminate distal part (probably without subapical flagellum) on distomesial part. Length ratio from first to third segments along mesial margin=1.0:0.62:0.77 (Fig. 1f). Antenna with elliptical scale, latter subequal in length to antennal peduncle, about 3 times as long as wide, setose all around margin (Fig. 1g). Mouthparts as illustrated (Fig. 2a-e).

Endopod of third thoracopod with ischium smooth on ventral margin; merus about 3 times as long as high, narrowing distally, armed with 2 flagellate spines near distal end of ventral margin, distoventral corner produced distally; carpopropodus slightly more than 2 times as long as high, ventral margin with marked swelling in proximal two-fifths, armed with 3 flagellate spines, 3 stout setae, and several fine setae on distal one-third; terminal claw strong, about half length of carpopropodus (Fig. 2f). Endopod of fourth thoracopod with 4-segmented carpopropodus. Endopods of fifth to eighth thoracopods each with 7-segmented carpopropodus (Fig. 2g). Pleopods each reduced to unsegmented lobe with pseudobranchial lobe (Fig. 2h, i). Exopod of uropod slightly more than 1.5 times as long as 

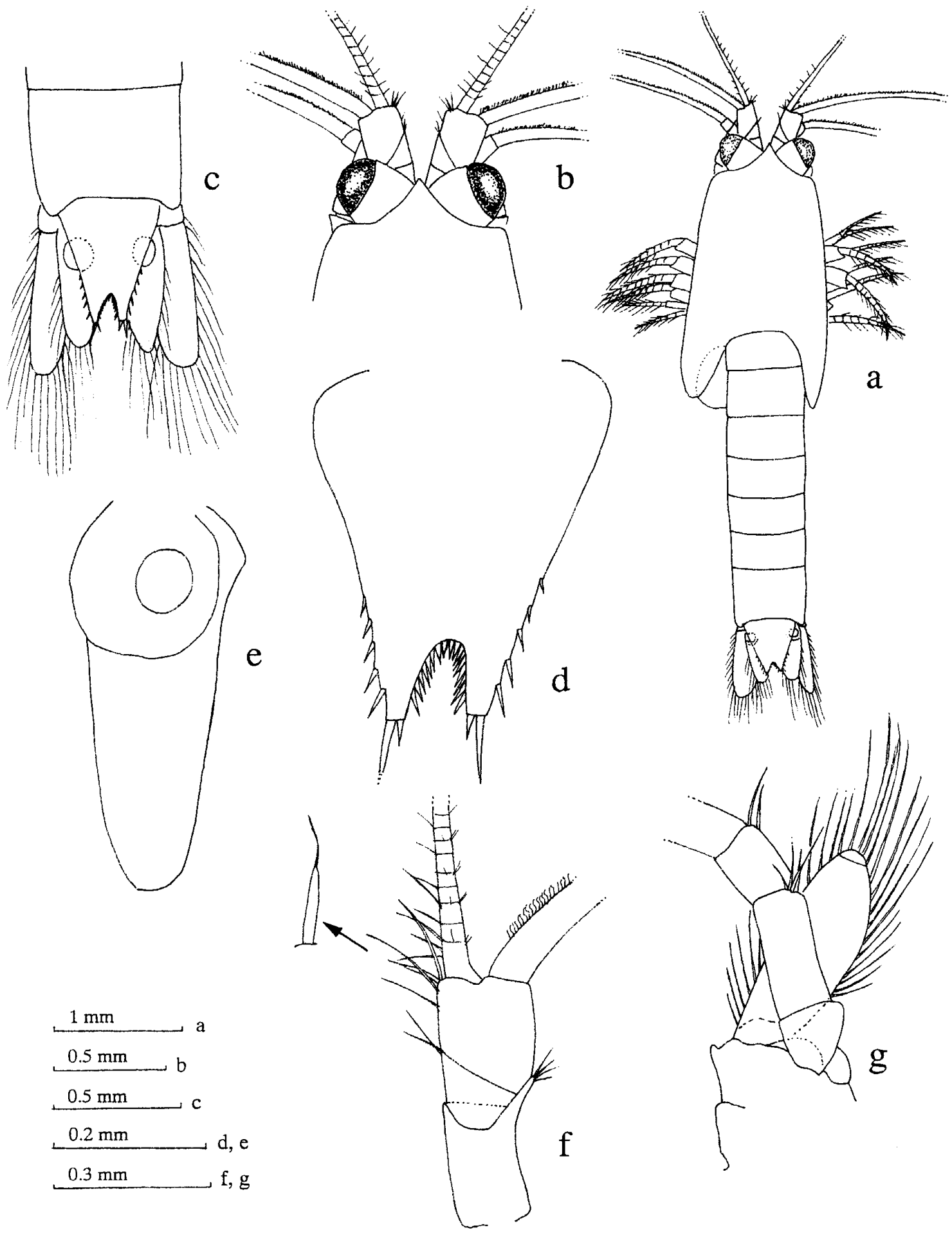

a

Fig. 1. Heteromysis dentata sp. nov. Holotype, ovigerous female $(4.4 \mathrm{~mm})$ : a, entire animal, dorsal; $\mathrm{b}$, anterior part of carapace and cephalic appendages, dorsal; $\mathrm{c}$, sixth abdominal somite, uropod, and telson, dorsal; d, telson, dorsal; e, endopod of right uropod, ventral; $f$, right antennule, dorsal, with detail of acuminate spine; g, right antenna, ventral. 


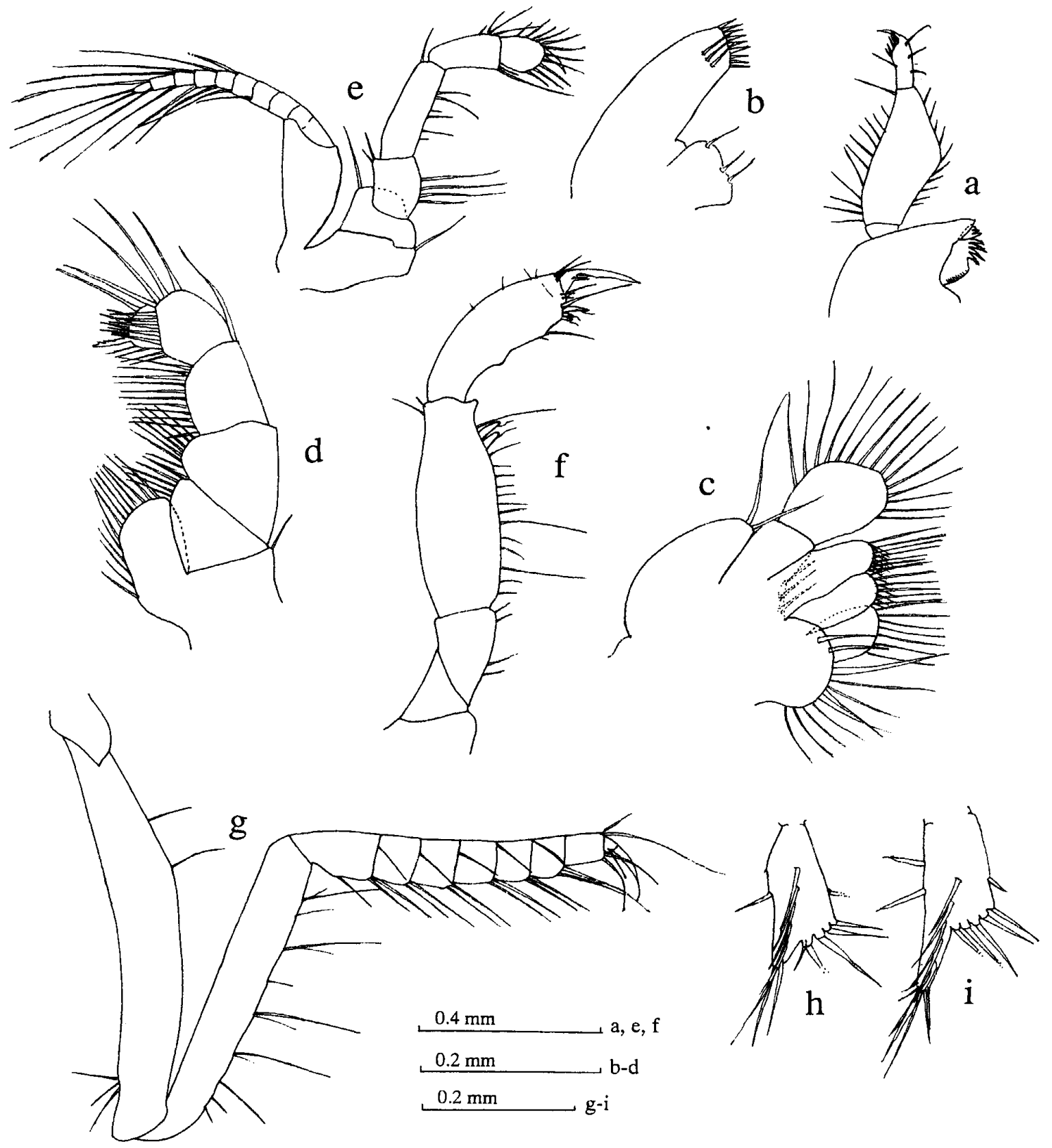

Fig. 2. Heteromysis dentata sp. nov. Appendages. Paratype, female $(4.0 \mathrm{~mm})(\mathrm{a}-\mathrm{f})$ and holotype, ovigerous female (4.4 mm) (g-i): a, right mandible, external; b, right maxillule, external; c, right maxilla, external; $d$, endopod of right first thoracopod, internal; e, right second thoracopod, external; $f$, endopod of right third thoracopod, lateral; $g$, endopod of right seventh thoracopod, lateral; h, left fourth pleopod, lateral; i, left fifth pleopod, lateral.

sixth abdominal somite; endopod 0.83 times as long as exopod, mesial margin weakly convex, unarmed (Fig. 1c, e).

Etymology. The specific name "dentata" (="toothed" in Latin) refers to the distinct distoventral tooth on the merus of the third thoracic endopod.

Distribution. Known only from the type locality. Both specimens were col- 
lected by brushing coral rubble partly embedded in the bottom sediment at a point of $30 \mathrm{~m}$ from the cave entrance at a depth of 2.0 to $2.4 \mathrm{~m}$.

Remarks. The new species has eyes without an ocular processes, the telson without lateral spines along its anterior half, and the posteromedian cleft of the telson armed with spinules along its entire margin. Of the known Indo-Pacific species of Heteromysis [excluding the subgenus Gnathomysis of Bacescu (1968)], the following seven species share these features (Table 1): $H$. australica Băcescu and Bruce, 1980; H. digitata W. M. Tattersall, 1927; H. gymnura W. M. Tattersall, 1922; H. heronensis Băcescu, 1979; H. inflaticauda Wang, 1998; $H$. proxima W. M. Tattersall, 1922; $H$. tethysiana Băcescu, 1983. The new species can easily be distinguished from all of these by the seven-segmented carpopropodus of the endopod in the posterior four pairs of thoracic limbs. The only possible exception is $H$. inflaticauda, in which the posterior thoracic limbs are unknown, but in this species the endopod of the uropod bears as many as 28 mesial spines (Wang 1998). In addition, the third thoracic endopod of $H$. dentata has a typical form, with a swelling along the proximal twofifths of the ventral margin of the carpopropodus, as well as an accompanying distinct, distoventral tooth on the merus.

Heteromysis dentata also resembles $H$. dispar Brattegard, 1970, from the western Atlantic Ocean, but the Atlantic species has a three-segmented carpopropodus in the seventh thoracic endopod and the telson abruptly narrows near its proximal end.(Brattegard 1970).

\section{Heteromysis longiloba sp. nov.}

(Fig. 3)

Material. Holotype: female, $3.0 \mathrm{~mm}$ in total length (WAM C 24974), stn. XM2, "Thundercliff Cave" diving site, northern side of Christmas Island, $10^{\circ} 28^{\prime} 21.3^{\prime} \mathrm{S}$, $105^{\circ} 36^{\prime} 24.6^{\prime \prime} \mathrm{E}, 30$ Nov. 1999 , limestone cave more than $100 \mathrm{~m}$ long, seemingly connected to land limestone caves, $1.3-6 \mathrm{~m}$ deep, totally dark inside, with calcareous and muddy sand bottom, salinity $32 \%$, leg. S. Ohashi, S. Kinjo, T. Kase, I. Hayami, Y. Kano, and L. Kirkendale.

Description. Body moderately robust, slightly depressed dorsoventrally. Rostrum triangular, directed slightly downwards, reaching midlength of first segment of antennular peduncle, lateral margin weakly concave (Fig. 3a). Carapace rounded dorsally, without cervical groove; posterior margin excavate, leaving last thoracic somite uncovered in dorsal view (Fig. 3a). Ventral sternites without processes.

Abdomen smooth; sixth somite longest, 1.57 times as long as fifth; length ratio of first to sixth somites $=0.91: 0.91: 0.82: 0.64: 0.64: 1.00$. No median ventral process present on pleon. Telson subtriangular, 1.27 times as long as sixth abdominal somite, 1.51 times as long as basal width; lateral margins weakly concave, armed with 8 or 9 spines along slightly more than distal half of each side, these spines increasing in length distally; apical lobe with 2 terminal spines, outer spine about 1.3 times as long as inner one; posteromedian cleft deep, occupying slightly less than half length of telson, armed with 8 large spinules only on anterior margin (Fig. $3 \mathrm{~b}$ ).

Eye with cornea well pigmented, slightly narrower than eyestalk, without ocular process (Fig. 3a). Antennular peduncle with first segment with anterolateral 




Fig. 3. Heteromysis longiloba sp. nov. Holotype, female $(3.0 \mathrm{~mm})$ : a, carapace and cephalic appendages, dorsal; b, telson, dorsal; c, right uropod, ventral; d, right antennule, dorsal, with detail of flagellate spine; e, right antenna, ventral; f, endopod of left seventh thoracopod, lateral; g, left third pleopod, lateral; h, left fourth pleopod, lateral.

corner strongly produced anteriorly and bearing several distal setae; second segment shortest, articulating obliquely with third segment, and with seta on distomesial margin; third segment widest, with seta at midlength of mesial margin, 
and 2 ordinary setae and stout spine distomesially, latter spine bearing subapical flagellum (Fig. 3d). Length ratio from first to third segments along mesial margin = $1.00: 0.50: 0.62$ (Fig. 3d). Antenna with elliptical scale, latter slightly shorter than antennal peduncle, 3.76 times as long as wide, setose all around margin (Fig. 3e).

All but seventh thoracopods missing; endopod of seventh thoracopod with 5segmented carpopropodus (Fig. 3f). Pleopods each reduced to unsegmented lobe with pseudobranchial lobe (Fig. 3g, h). Uropod extending beyond posterior end of telson by one-third of length of exopod; endopod slightly shorter than exopod, slightly curving inward, armed with 12 spines along entire mesial margin (Fig. 3c).

Etymology. The specific name "longiloba" (="long lobe" in Latin) refers to the long apical lobe of the telson.

Distribution. Known only from the type locality. The specimen was obtained by brushing coral rubble partly embedded in the bottom sediment at a point of $30 \mathrm{~m}$ from the cave entrance at a depth of $5.5 \mathrm{~m}$.

Remarks. This species displays the following combination of major features: eyes without ocular processes; lateral margins of telson unarmed along almost all of anterior half; posteromedian cleft of telson armed with spinules only along anterior margin. The new species resembles the Indo-Pacific $H$. spinosa Băcescu, 1986, but the latter species differs immediately in having a reduced cornea of the eye and an antennal scale that is longer than the antennal peduncle (Băcescu 1986).

The following nine Atlantic species share the features described above: $H$. actiniae Clarke, 1955; $H$. bermudensis Sars, 1885; H. elegans Brattegard, 1974; H. filtelsona Modlin, 1984; H. floridensis Brattegard, 1969; H. formosa Smith, 1873; H. hopkinsi Modlin, 1984; H. mariani Băcescu, 1970; H. nouveli Brattegard, 1969. Of these, $H$. actiniae, $H$. elegans, and $H$. floridensis have a slightly curving uropodal endopod as in $H$. longiloba. However, $H$. actiniae bears 40 or more mesial spines on the uropodal endopod and $H$. elegans has no such spines (Brattegard 1969, 1974). The telson of $H$. floridensis is constricted at midlength (Brattegard 1969) as opposed to having an evenly concave lateral margin as in $H$. longiloba.

\section{Discussion}

The taxonomy of heteromysids is still far from complete (cf. Bravo and Murano 1996; Nouvel et al. 1999). There is also some confusion over the division of the genus Heteromysis into subgenera. The following four subgenera have been proposed by Băcescu (1968, 1976): Gnathomysis, Heteromysis, Neoheteromysis, and Olivaemysis. However, several authors seem not to have given full consent to Băcescu's scheme (cf. Brattegard 1970, 1974; Modlin 1984, 1987), and many species are not attributed to a subgenus. Bamber (2000) states that Heteromysis cyanogoleus from the Bahamas has features of both the subgenera Heteromysis and Olivaemysis in that the male pleopods are characteristic of the former but the antennule is characteristic of the latter. Similarly, $H$. dentata in the present study does not conform to any proposed subgenus in terms of both the absence of a flagellate spine on the antennule and the ventral sternal processes of the thorax. This suggests that the current concept of subgenera is insufficient at least as regards Heteromysis and Olivaemysis.

The "Heteromysis harpax" species group [i.e. Gnathomysis of Băcescu (1968)] is 
Table 1. Indo-Pacific species of Heteromysis and comparison of key characters.

\begin{tabular}{|c|c|c|c|c|}
\hline $\begin{array}{c}\text { Species } \\
\text { and } \\
\text { author/references }\end{array}$ & $\begin{array}{c}\text { Ocular process } \\
\text { or } \\
\text { projection }\end{array}$ & $\begin{array}{l}\text { Lateral margin of } \\
\text { telson with } \\
\text { spines along: }\end{array}$ & $\begin{array}{l}\text { Posteromedial cleft of } \\
\text { telson with spine } \\
\text { (or spinules) along: }\end{array}$ & $\begin{array}{l}\text { Number of mesial } \\
\text { spines on } \\
\text { uropodal endopod }\end{array}$ \\
\hline H. abrucei Băcescu, 1979 & present & entire margin & anterior $1 / 2$ & $2-4$ \\
\hline $\begin{array}{l}\text { H. australica Băcescu and } \\
\text { Bruce, } 1980\end{array}$ & absent & posterior $1 / 2$ & entire margin & 1 \\
\hline H. brucei O. S. Tattersall, 1967 & present & entire margin & anterior $1 / 2$ & 5 \\
\hline H. communis Băcescu, 1986 & ? present & posterior $1 / 2$ & entire margin & $4-5$ \\
\hline $\begin{array}{l}\text { H. dentata Hanamura and } \\
\text { Kase sp. nov. }\end{array}$ & absent & posterior $1 / 2$ & entire margin & 0 \\
\hline H. digitata W. M. Tattersall, 1927 & $\begin{array}{c}\text { present } \\
\text { (overhanging rim) }\end{array}$ & posterior $1 / 2$ & entire margin & 0 \\
\hline H. essingtonensis Murano, 1988 & absent & entire margin & anterior $1 / 2$ & $13-15$ \\
\hline $\begin{array}{l}{ }^{*} H . \text { gerlachei } \\
\quad \text { (Bonnier and Pérez, 1902) }\end{array}$ & absent & posterior $1 / 2$ & entire margin & many \\
\hline H. gracilis Murano, 1988 & absent & posterior $4 / 5-5 / 6$ & anterior $3 / 4$ & 17 \\
\hline H. gymnura W. M. Tattersall, 1922 & absent & posterior $1 / 2$ & anterior $4 / 5$ & 0 \\
\hline${ }^{*} H$. harpax (Hilgendorf, 1879) & absent & posterior $1 / 2$ & entire margin & $15-17$ \\
\hline $\begin{array}{l}{ }^{*} H \text {. harpaxoides Bacescu and } \\
\text { Bruce, } 1980\end{array}$ & $\begin{array}{c}\text { absent } \\
\text { (cornea reduced) }\end{array}$ & posterior $1 / 2$ & entire margin & $14-17$ \\
\hline H. heronensis Băcescu, 1979 & absent & posterior $1 / 2$ & entire margin & 2 (widely spaced) \\
\hline H. inflaticauda Wang, 1998 & absent & posterior $1 / 2$ & anterior $4 / 5$ & 28 \\
\hline${ }^{*} H$. kossmanni Nouvel, 1964 & $\begin{array}{c}\text { absent } \\
\text { (cornea reduced) }\end{array}$ & posterior $3 / 5$ & entire margin & $?$ \\
\hline $\begin{array}{l}\text { H. longiloba Hanamura and } \\
\text { Kase sp. nov. }\end{array}$ & absent & posterior $3 / 5$ & only anterior margin & 12 \\
\hline H. macrophthalma Băcescu, 1983 & $\begin{array}{c}\text { present } \\
\text { gap at midlength }\end{array}$ & $\begin{array}{l}\text { entire margin, } \\
\text { with unarmed }\end{array}$ & anterior $2 / 3$ & $2-4$ \\
\hline H. macropsis Pillai, 1961 & absent & posterior $1 / 2$ & entire margin & 8 \\
\hline H. maxima Murano, 1998 & present & entire margin & entire margin & $4-5$ \\
\hline H. minuta O. S. Tattersall, 1967 & $\begin{array}{c}\text { present } \\
\text { (cornea reduced) }\end{array}$ & posterior $2 / 5$ & anterior part & $20-22$ \\
\hline H. odontops Walker, 1898 & present & entire margin & entire margin & 4 \\
\hline H. pacifica O. S. Tattersall, 1967 & $\begin{array}{l}\text { present } \\
\text { gap at midlength }\end{array}$ & $\begin{array}{l}\text { entire margin, } \\
\text { with unarmed }\end{array}$ & anterior $4 / 5$ & 3 \\
\hline $\begin{array}{l}\text { H. panamaensis } \\
\text { O. S. Tattersall, } 1967\end{array}$ & absent & entire margin & entire margin & 1 \\
\hline H. proxima W. M. Tattersall, 1922 & absent & posterior $1 / 2$ & entire margin & 1 \\
\hline H. quadrispinosa Murano, 1988 & present & entire margin & entire margin & 4 \\
\hline H. sexspinosa Murano, 1988 & $\begin{array}{l}\text { present } \\
\text { unarmed gap } \\
\text { at midlength }\end{array}$ & $\begin{array}{l}\text { entire margin, } \\
\text { rarely with }\end{array}$ & entire margin & 2 \\
\hline $\begin{array}{l}\text { H. singaporensis } \\
\quad \text { O. S. Tattersall, } 1967\end{array}$ & $\begin{array}{c}\text { absent } \\
\text { (stalk hispid) }\end{array}$ & posterior $4 / 5$ & entire margin & 13 \\
\hline $\begin{array}{l}{ }^{*} H . \text { stellata } \text { Băcescu and } \\
\text { Bruce, } 1980\end{array}$ & absent & posterior $1 / 2$ & entire margin & $15-17$ \\
\hline H. spinosa Băcescu,1986 & absent & posterior $1 / 2$ & anterior $1 / 2-1 / 3$ & $6-11$ \\
\hline H. tenuispina Murano, 1988 & present & posterior $2 / 5$ & anterior $1 / 2$ & 9 \\
\hline H. tethysiana Băcescu, 1983 & absent & posterior $2 / 5$ & entire margin & 0 \\
\hline H. waitei W. M. Tattersall, 1927 & present & $\begin{array}{l}\text { almost entire margin } \\
\text { except for dista } \\
\text { and proximal ends }\end{array}$ & entire margin & $3-4$ \\
\hline H. xanthops Ii, 1964 & absent & posterior $1 / 2$ & entire margin & $14-15$ \\
\hline H. zeylanica W. M. Tattersall, 1922 & present & $\begin{array}{l}\text { entire margin, with } \\
\text { unarmed gap } \\
\text { at midlength }\end{array}$ & anterior $1 / 2-2 / 3$ & $11-13$ \\
\hline
\end{tabular}

${ }^{*} H$. harpax species group [subgenus Gnathomysis of Băcescu (1968)] 
characterized by a very robust third thoracopod with a serrated ischium. Species of this group can be recognized easily by this structure (Nouvel 1964; Băcescu 1968, 1980), and, consequently, the group appears to be isolated from the others. The subgenus Neoheteromysis contains a single species, $H$. muelleri Băcescu, 1976, distinguished from all the remaining species of Heteromysis by its remarkable fourth pleopods with extraordinarily long apical setae (Băcescu 1976), for which Nouvel et al. (1999) raised it to full generic rank.

Although a degree of confusion remains in the taxonomy of Heteromysis, our knowledge of the Indo-Pacific species has progressed greatly in the last two decades and 33 species are recognized from the region, including the two new species in this study. These species are listed in Table 1 along with their major characteristics.

Species of Heteromysis have been reported from diverse types of habitat, and most species have a cryptic mode of existence, living in association with sponges and corals or as commensals with various invertebrates (see also Müller 1993). Only three species of Heteromysis have as yet been recorded from submarine caves (Băcescu and Iliffe 1986; Bamber 2000). Submarine caves in the Indo-Pacific remain largely unexplored, and surveys of this habitat will likely produce further undiscovered species of Heteromysis in the region.

\section{Acknowledgements}

We are most grateful to Messrs. S. Ohashi and S. Kinjo, Okinawa, Japan, for collecting the material, to Mr. M. Cathrein of the Indian Ocean Diving Academy, Christmas Island, for diving facilities, and to Dr. S. Slack-Smith of the Western Australian Museum and Dr. D. Slip of Parks Australia, Christmas Island, for assisting with the procedures for obtaining research permits. We thank Dr. M. Murano of METOCEAN for reading a draft of this manuscript and making valuable suggestions. We further express our sincere thanks to reviewers of the journal for their constructive comments. This study was supported in part by a grant from the Ministry of Education, Science, Sports and Culture to the second author (TK) (Project Nos 11691196 and 11833018).

\section{References}

Băcescu, M. 1968. Heteromysini nouveaux des eaux cubaines: trois espèces nouvelles de Heteromysis et Heteromysoides spongicola n. g. n. sp. Revue Roumaine de Biologie, Série de Zoologie 13: 221-237.

Băcescu, M. 1976. Contribution à la connaisance des Mysidacés (Crustacés) de la côte lybienne, avec la description de deux nouvelles espèces, Neoheteromysis muelleri $\mathrm{n}$. sg. $\mathrm{n}$. sp. et Heteromysis lybiana n. sp. Revue Roumaine de Biologie, Série de Biologie Animale 21: 85-91.

Băcescu, M. 1979. A small contribution to the knowledge of the mysids from the north-eastern Great Barrier Reef of Australia. Travaux du Musée d'Histoire Naturelle "Grigore Antipa" 20: 143-147.

Băcescu, M. 1983. New Heteromysini from the coral area near Heron Island (SE Queensland)- 
Australia. Revue Roumaine de Biologie, Série de Biologie Animale 28: 3-11.

Băcescu, M. 1986. Two new species of Heteromysis from the coral reefs of northern Australia. Travaux du Musée d' Histoire Naturelle "Grigore Antipa" 28: 19-24.

Băcescu, M. and Bruce, A. J. 1980. New contributions to the knowledge of the representatives of genus Heteromysis s. l. from the Australian coral reefs. Travaux du Musée d' Histoire Naturelle "Grigore Antipa" 21: 63-72.

Băcescu, M. and Iliffe, T. M. 1986. Bermudamysis g. n., Platyops g. n. and other mysids from Bermudian caves. Stygologia 2: 93-104.

Bamber, R. N. 2000. A new species of Heteromysis (Crustacea: Mysidacea) from a "blue hole" in the Bahamas. Species Diversity 5: 129-134.

Bonnier, J. and Pérez, C. 1902. Sur un Crustacé commensale des Pagures, Gnathomysis gerlachei nov. sp., type d'une famille nouvelle de Schizopodes. Comptes Rendus Hebdomadaires des Séances de l'Académie des Sciences 134: 117-119.

Brattegard, T. 1969. Marine biological investigations in the Bahamas 10. Mysidacea from shallow water in the Bahamas and southern Florida. Part 1. Sarsia 39: 17-106.

Brattegard, T. 1970. Mysidacea from shallow water in the Caribbean Sea. Sarsia 43: 111-154.

Brattegard, T. 1974. Additional Mysidacea from shallow water on the Caribbean coast of Colombia. Sarsia 57: 47-86.

Bravo, M. R. and Murano, M. 1996. A new species of the genus Pseudomysidetes (Mysidacea) from Japan and reallocation of this genus to the Heteromysini. Crustaceana 69: 476-484.

Hilgendorf, F. 1879. Die von Herrn W. Peters in Moçambique gesammelten Crustaceen. Monatsberichte der K. Preussischen Akademie der Wissenschaften zu Berlin: 782-851, pls $1-4$.

Ii, N. 1964. Fauna Japonica, Mysidacea (Crustacea). Biogeographical Society of Japan, Tokyo, $610 \mathrm{pp}$.

Modlin, R. F. 1984. Mysidacea from the Florida Middle Ground, northeast Gulf of Mexico, with descriptions of three new species of Heteromysis and a key to the Heteromysini of the western Atlantic. Journal of Crustacean Biology 4: 278-297.

Modlin, R. F. 1987. Heteromysini from Grand Bahama Island: Description of Heteromysis agelas, new species, first description of male $H$. floridensis, and notes on $H$. guitarti (Crustacea: Mysidacea). Proceedings of the Biological Society of Washington 100: 296-301.

Müller, G.-H. 1993. World Catalogue and Bibliography of the Recent Mysidacea. Laboratory for Tropical Ecosystems Research and Service, Wetzler, $491 \mathrm{pp.}$

Murano, M. 1988. Heteromysids (Crustacea; Mysidacea) from northern Australia with description of six new species. The Beagle, Records of the Northern Territory Museum of Arts and Sciences 5: 27-50.

Murano, M. 1998. Further study on Australian heteromysids (Crustacea: Mysidacea). The Beagle, Records of the Museums and Art Galleries of the Northern Territory 14: 29-39.

Nouvel, H. 1964. Heteromysis gerlachei (Bonneir \& Pérez) et les espèces actuellement confondues sous le nom d'Heteromysis harpax (Crustacea Mysidacea). Zoologische Mededelingen 39: 37-44.

Nouvel, H., Casanova, J.P. and Lagardère, J.-P. 1999. Ordre Mysidacés (Mysidacea Boas 1883). Pp. 39-86. In: Forest, J. (ed.), Crustacés Péracarides, Traité de Zoologie, Anatomie, Systématique, Biologie. Tome VII Fascicule IIIA. Memoires de l'Institut Océanographique 19: 1-450.

Pillai, N. K. 1961. Additions to the Mysidacea of Kerala. Bulletin of the Central Research Institute, University of Kerala, Trivandrum 8: 15-28.

Smith, S. I. 1873. Report upon the invertebrate animals of Vineyard Sound and the adjacent 
waters, with an account of the physical characters of the region. Report of the Commission of Fisheries and Fish 1871-1872: 295-747 (not seen).

Tattersall, O. S. 1967. A survey of the genus Heteromysis (Crustacea: Mysidacea) with descriptions of five new species from tropical coastal waters of the Pacific and Indian Oceans, with a key for the identification of the known species of the genus. Transactions of the Zoological Society of London 31: 157-193.

Tattersall, W. M. 1922. Indian Mysidacea. Records of the Indian Museum 24: 445-504.

Tattersall, W. M. 1927a. Australian opossum shrimps (Mysidacea). Records of the South Australian Museum 3: 235-257.

Tattersall, W. M. 1927b. Cambridge Expedition to the Suez Channel. Report on the Crustacea Mysidacea. Transactions of the Zoological Society of London 22: 185-198.

Walker, A. O. 1898. Crustacea collected by A. W. Herdman, F. R. S. in Puget Sound, Pacific coast of North America, Sept. 1897. Proceedings and Transactions of the Liverpool Biological Society 12: 268-287.

Wang, S. 1998. On new and rare species of Mysidacea (Crustacea) from the northern South China Sea. Studia Marina Sinica 40: 199-244. 